\title{
ETERNIDADE
} FRÁGIL

Ensaio de temporalidade na arte

\section{Eternidade Frágil: Um exemplo de História à Serviço da Vida.}

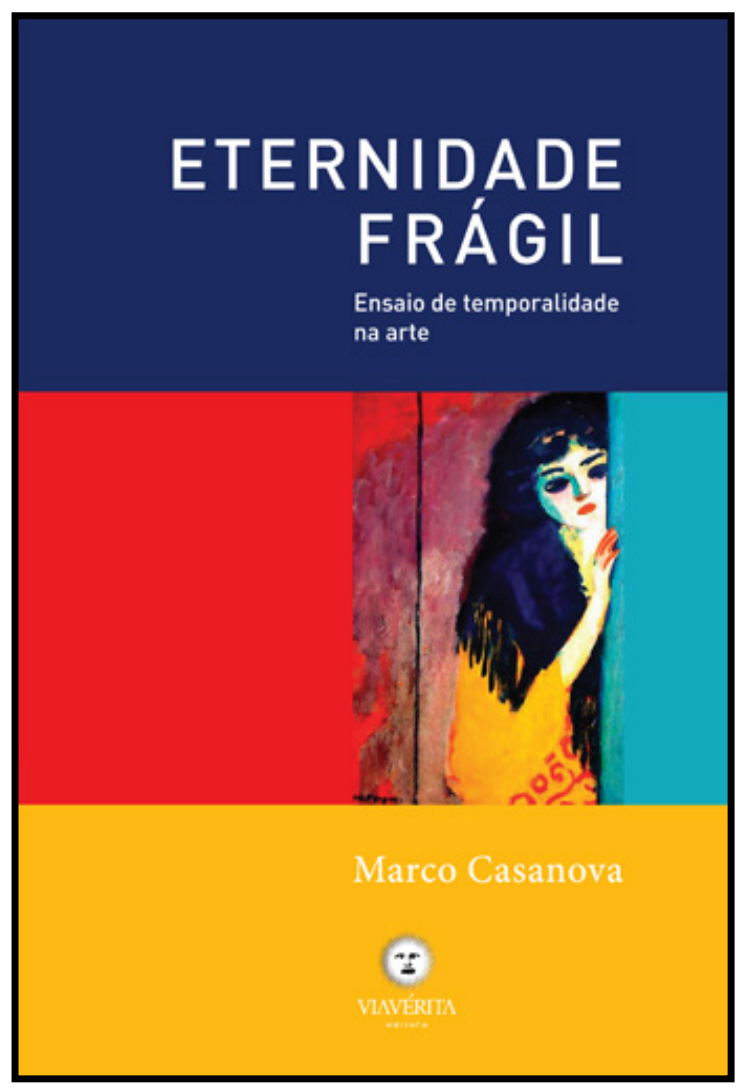

por Renan da Rocha Cortez

renancortez22@gmail.com

Doutorando UFMG / CAPES

Casanova, Marco Antônio. Eternidade Frágil: ensaio de temporalidade na arte. Rio de Janeiro: Via Verita, 2013. 
"Eternidade Frágil: um exemplo de história à serviço da vida" por Renan da Rocha Cortez resenha crítica do livro de Marco

Casanova "Eternidade Frágil:

ensaio de temporalidade na arte"

\section{Introdução}

Em alguns casos, a fronteira que promove uma separação entre a história da filosofia e a filosofia não é muito clara. Mas se o problema fosse somente de fronteira, conseguiríamos com alguma facilidade iluminar a confusão e perceber com o mínimo de clareza o confuso. Contudo, sabemos que os lados divididos pela fronteira não são tão facilmente definíveis: muito pelo contrário, parecem terras móveis que zombam da fixidez dos mapas. Ao percebemos que a tentativa de identificação dos lados e das fronteiras já parece pressupor uma atividade filosófica que, por sua vez, nos remete ao estudo da historiografia, acenamos gestos de despedida para as bússolas e continuamos a tatear na escuridão.

Na década de 70 do século 19, o filólogo F. Nietzsche expressou em alguns textos certo incômodo em relação ao apreço exagerado que diversos intelectuais nutriam pelo senso histórico. Na Segunda consideração intempestiva, afirmou que os historiadores esforçavam-se para estudar com objetividade os acontecimentos do passado, mas adotavam uma postura de indiferença diante da necessidade de criação de novos acontecimentos relevantes.

Há duas críticas a esse tipo de postura nas Considerações Intempestivas. A primeira pode ser considerada uma crítica epistemológica tímida, não desenvolvida com o rigor necessário, mas rica em conseqüências. A segunda, uma crítica "moral", na qual Nietzsche apresenta em crisálida a preocupação com um problema que tornou-se fundamental em sua obra posterior: o valor moral da verdade.

A primeira diz respeito à pretensão de objetividade dos historiadores ${ }^{1}$. Nietzsche apresenta certo ceticismo no tocante à possibilidade de um acesso objetivo aos fatos do passado. Por estar contaminado pelos preconceitos e visões de mundo de sua época, o historiador sempre projeta o presente no passado, o que torna impossível o conhecimento do "passado em si mesmo"2.

1 "Estes historiadores ingênuos chamam de 'objetividade' o fato de avaliar as opiniões e os atos passados pelas opiniões correntes do momento presente, onde eles de resto encontram um cânone de todas as verdades; o seu trabalho consiste em acomodar o passado na trivialidade atual. Eles chamam, ao contrário, de 'subjetiva' qualquer historiografia que não admita a canonicidade destas opiniões comuns. "(NIETZSCHE, 2003)

2 Esse tema exige uma apreciação mais demorada. A apresentação acima é somente o ponto de partida para um amplo debate. No artigo Nietzsche's aesthetics and the question of hermeneutic interpretation (1986), Nicholas Davey tentou provar que em A Origem da tragédia Nietzsche apresentou uma possível resposta para o problema do acesso ao passado. Segundo o autor, essa resposta se aproxima da noção de fusão de horizontes. Contudo, Davey não comenta nada sobre a segunda intempestiva. Seria importante saber se nesse texto há alguma possibilidade que nos permita pensar em algo semelhante à noção de fusão de horizontes. Não pretendo defender uma posição detalhada sobre a postura teórica de Nietzsche. Contudo, não parece muito difícil confessar que o filósofo adota uma postura cética. Propositalmente deixo o termo cético sem maiores qualificações. Acredito que somente a partir dessa informação geral qualquer 
"Eternidade Frágil: um exemplo de história à serviço da vida" por Renan da Rocha Cortez

É ingenuidade acreditar que essa crítica obrigaria Nietzsche à concluir que todos os juízos sobre o passado são equivalentes em termos de validade. $\mathrm{O}$ filósofo não está adotando o reino livre da imaginação como critério último do conhecimento histórico. Tenho certeza de que Nietzsche não oscilaria em considerar falso o juízo "o burguês Alexandre o Grande, ao lado de outros rebeldes, tomou a bastilha em 1789". Na verdade, se qualquer indivíduo defendesse a legitimidade desse juízo, o princípio de caridade o obrigaria a empreender um esforço hercúleo de tradução e organização do aparente absurdo ${ }^{3}$. Enfim, esse tipo de "objetividade elementar" não é o que interessa ao filósofo. Tanto que Nietzsche não hesita em constatar a importância parcial do trabalho de coleção dos fatos empíricos. O contato permanente com documentos empíricos é a exigência mais básica, ao mesmo tempo "plebéia" e imprescindível ${ }^{4}$.

A crítica à objetividade deve ser localizada em um ponto específico. Nietzsche se refere ao modo como os fatos empíricos são organizados em contextos semânticos ${ }^{5}$. Apesar de não fornecer muitos detalhes sobre o assunto, as imagens utilizadas pelo filósofo apontam para essa direção. Em continuidade com essas imagens - mas com honestidade para confessar que isso está além do que Nietzsche apresenta - afirmo que a parcialidade pode estar relacionada à opções circunstanciais tomadas por um historiador: a atribuição de relevância a certos temas de estudo, a perspectiva metodológica utilizada, os critérios que orientam a escolha de documentos, a determinação de um plano capaz de fornecer a cada fato particular um significado específico no interior de uma sucessão de acontecimentos etc.

Além de defender a impossibilidade, Nietzsche critica o valor da imparcialidade. Obviamente o objeto dessa crítica não é a imparcialidade real. O motivo é evidente: a postura imparcial, apesar de simulada, não existe. $\mathrm{O}$ desinteresse real é uma impossibilidade epistemológica. Contudo, nada impede que os historiadores simulem a imparcialidade e transformem o desinteresse em uma virtude epistêmica desejável.

discussão pode vir à tona. Outra referência interessante acerca desse tema é o artigo Nietzsche and neokantian historiography: points of contact (2013), de Anthony K. Jensen. Nesse texto, o autor apresenta as relações entre a filosofia de Nietzsche e as principais teorias da história neokantianas. Mas o mais interessante é a exposição do autor sobre o modo como F. Nietzsche adotou o idealismo de Lange em suas posições sobre filosofia da história. O texto fornece uma base para cogitarmos a hipótese de que as reflexões sobre a história talvez sejam uma ramificação de algumas posições epistemológicas (a teoria do erro) mais gerais de Nietzsche.

3 Com o objetivo de mostrar que a crítica à objetividade não tem como conseqüência a arbitrariedade, Nietzsche insere no parágrafo 6 da segunda intempestiva a noção de justiça.

$4 \mathrm{O}$ uso do termo "plebeu" é só um modo de manter alguma fidelidade ao espírito do texto de Nietzsche. Sem dúvida, um vocabulário mais adequado à sensibilidade moral democrática seria mais elegante.

5 Ler a parte 6 da Segunda Intempestiva, especificamente os dois últimos parágrafos. 
"Eternidade Frágil: um exemplo de história à serviço da vida" por Renan da Rocha Cortez resenha crítica do livro de Marco

Casanova "Eternidade Frágil:

ensaio de temporalidade na arte"

Essa simulação de imparcialidade produz conseqüências negativas para a cultura e para o conhecimento. Nietzsche defende que o historiador deve se relacionar com o passado de outro modo. Sua crítica à imparcialidade está assentada em um critério normativo, cuja formulação o filósofo encontra em Goethe e apresenta logo na primeira passagem da segunda intempestiva: "De resto, me é odioso tudo o que simplesmente me instrui, sem aumentar ou imediatamente vivificar a minha atividade." (NIETZSCHE, 2003)

O problema do historiador que simula a imparcialidade está na ausência de vitalidade do seu trabalho: a mera descrição de fatos do passado em nada contribui para a vida. Em contrapartida, Nietzsche defende que a pesquisa histórica deve ter como meta a ação no presente. As informações do passado precisam servir como estímulo para novas obras, assim como para projetos de transformação do porvir. De acordo com o autor, a cultura moderna, na qual o senso histórico encontrava-se intensamente desenvolvido, havia se transformado em um mero saber sobre outras culturas. Contra isso, Nietzsche propôs uma relação com o passado na qual o historiador deve usar a história como um instrumento para a produção de uma cultura autêntica.

Em um exercício especulativo, tomo a liberdade de propor essa ideia de uma História à serviço da vida como um padrão de comportamento possível para o intérprete da história da filosofia. Acredito que esse "modelo" pode enfraquecer a importância da difícil questão relativa às diferenças entre as atividades do filósofo e do historiador da filosofia.

Primeiro é importante mencionar que Nietzsche, mesmo ciente do potencial inibidor do conhecimento histórico, não desvaloriza o estudo do passado. Isso nos permite deduzir que uma filosofia do presente não deve excluir o diálogo com a tradição da história da filosofia. Muito pelo contrário, esse diálogo é inevitável. Diferentemente de uma postura "cartesiana", Nietzsche não poderia propor que o início de um filosofar autoral e atual dependa de uma exclusão das informações da tradição, pois a suspensão do horizonte histórico é impossível. A filosofia do presente sempre carrega nas costas as tradições sedimentadas do passado. Visitar os filósofos clássicos é uma postura recomendável. Melhor: independentemente de uma opção pela intensificação do diálogo com a tradição, o homem do presente já está sempre contaminado - sem necessariamente saber - por redes de significados que remontam à decisões históricas anteriores, seja de filósofos ou não. Contudo, por mais que o peso da história incomode as costas, ele não pode impedir o autor do presente de caminhar. É preciso caminharcom o peso. Sem posturas radicais de vanguardas inocentes, mas também sem o silêncio resignado do corcunda. 
resenha crítica do livro de Marco

Casanova "Eternidade Frágil:

ensaio de temporalidade na arte"

Além disso, a postura diante do passado não pode ser aquela adotada pelo erudito curioso. Esse tipo se assemelha ao colecionador de imagens empíricas, aquele que realiza o trabalho plebeu e imprescindível. Sem dúvida, o contato constante com a diversidade das fontes empíricas - no caso, os documentos deixados pelos filósofos - é inevitável. Mas isso não é questão de disputa. $\mathrm{O}$ confronto com as informações empíricas é evidente. No contexto da crítica nietzschiana, o problema reside na determinação dessa postura como o fim último da ação do intérprete. Ela é um meio: sem ela, o estudo sério é impossível. Mas somente com ela, indesejável. O contato com a multiplicidade dos dados empíricos deve ser guiado pelos interesses e projetos específicos de uma perspectiva do presente. Somente assim o indivíduo pode evitar o mergulho e o conseqüente afogamento no mar infinito de informações da história.

Que fique claro: a interpretação à serviço da vida e a tradição exigem do historiador um domínio técnico de autores e contextos teóricos, assim como certa liberdade para iniciar diálogos criativos, nos quais os filósofos da tradição tentam responder a perguntas que nunca formularam.

Assim, retornamos ao início. Talvez não seja necessário saber se em determinados casos alguém está praticando filosofia ou história da filosofia. O que importa é o comportamento do intérprete, o gesto que ele apresenta em sua lida com a tradição. Em suma: que haja autonomia para iniciar um diálogo com os clássicos e sabedoria para ouvir o que eles dizem. Não o que disseram. O que dizem especificamente na circunstância deste diálogo.

\section{Considerações sobre a estrutura da obra}

Pretendo mostrar nessa resenha que o mais recente livro de Marco Casanova é um exemplo de aplicação do padrão possível de interpretação que foi mencionado acima. A introdução, portanto, não foi capricho de arbítrio, mas expressão de fidelidade aos interesses do autor de Eternidade Frágil. A apresentação da relação entre atualidade e tradição, tal como formulada anteriormente, possui como base bibliográfica privilegiada o livro Instante extraordinário, obra na qual Marco Casanova expôs um comentário - e um pouco mais do que isso sobre a filosofia de Nietzsche.

O autor lançou recentemente o primeiro volume da obra Eternidade Frágil, cujo subtítulo é Ensaios sobre temporalidade e arte. No total, a obra terá quatro 
"Eternidade Frágil: um exemplo de história à serviço da vida" por Renan da Rocha Cortez

volumes. Casanova já está escrevendo o segundo, que se chamará Eternidade frágil: ensaio de temporalidade na ação.

Antes de Eternidade Frágil, M. Casanova já havia escrito outros livros: Nada a caminho, Compreender Heidegger e Instante Extraordinário. Isto sem mencionar as numerosas traduções com comentários e os artigos em geral. O livro mais recente retoma algumas importantes interpretações já apresentadas nas obras anteriores. Por exemplo: a ênfase no fracasso de Ser e Tempo e a defesa da filosofia do segundo Heidegger, as considerações sobre niilismo e técnica, a interpretação da vontade de poder etc. Há, contudo, uma diferença substancial no modo como esses temas são apresentados em Eternidade Frágil. Se antes os comentários pareciam representar os resultados específicos de uma determinada pesquisa, em Eternidade Frágil eles estão rigorosamente articulados no interior de um projeto único.

Além dessa retomada diferenciada, a obra apresenta também uma série de outros temas que não aparecem registrados nos livros citados anteriormente. Seleciono alguns: a exposição sintética e rigorosa da filosofia de Dilthey, a análise de $A$ origem da obra de arte, a apresentação do pessimismo hiperbólico nietzschiano, a exposição da segunda voz do eterno retorno, a aplicação do método fenomenológico na análise das obras de arte etc.

A multiplicidade de temas pode fornecer ao leitor a impressão de que o livro se resume a um exercício vertiginoso de erudição. Todavia, como já foi mencionado, M. Casanova propõe um diálogo com autores clássicos digno de uma história voltada para a vida. Além do contato direto com os textos primários e das interpretações rigorosas e criativas, há um projeto central do autor que fornece a cada um desses temas uma razão de ser no interior da obra. Eles não estão isolados, não são meros comentários fragmentados. Cada reconstrução possui uma função específica no interior do projeto geral. A articulação cuidadosa entre a unidade do projeto e a multiplicidade de temas é um dos grandes méritos da obra.

Usando uma imagem frequente do vocabulário do autor, é possível afirmar que essa obra é uma grande constelação formada por pequenas constelações. A grande consiste na união entre o projeto central e os temas, ou seja, o todo propriamente dito da obra. Mas além disso, muitos temas apresentados também são constelações, pois guardam alguma independência em relação ao todo. É possível acompanhar, por exemplo, a exposição da filosofia de Hegel sem precisar compreender o projeto principal da obra em todos seus detalhes e desdobramentos. Devido ao estilo do autor, diversos capítulos possuem uma estrutura que garantem ao leitor a compreensão completa da parte em questão. Não à toa, 
em muitos momentos, Casanova precisa mostrar ao leitor a articulação existente entre as apresentações particulares e o desenvolvimento da espinha dorsal do seu próprio projeto. É visível a preocupação do autor em não perder o "fio da meada" a cada nova avalanche de informações filosóficas. Por esse motivo, muitos momentos da obra são didáticos, pois ajudam o leitor a relembrar todos os passos dedutivos dados anteriormente e a relacioná-los com o que acabou de ser lido.

Essa estrutura possibilita modos diversos de leitura. Há um modo de entrar no livro que talvez seja o mais adequado e rico em termos de conseqüências intelectuais para o leitor.

Esse modo exige do leitor a compreensão do projeto principal e o acompanhamento dos seus desdobramentos. Esse projeto, apresentado logo na introdução e reapresentado em diversos outros momentos da obra, é efetivamente a contribuição que Marco Casanova, em primeira pessoa, tem à fornecer para os seus leitores. Os desdobramentos do projeto são as reconstruções de alguns contextos teóricos, as interpretações originais sobre alguns autores e a aplicação do método fenomenológico na análise das obras de artes. A articulação entre o projeto e esses desdobramentos é o que caracteriza a totalidade da obra, o que chamei anteriormente de grande constelação.

Como a grande constelação é formada por pequenas, há também outros modos possíveis de usar o livro. A obra fornece muitas reconstruções de contextos teóricos. Por esse motivo, ela pode ser utilizada como fonte de consulta. Impossível deixar de mencionar que a primeira parte inteira tornaria qualquer bibliografia sobre filosofia da história um pouco mais rica.

Além das reconstruções, o livro apresenta algumas interpretações singulares, especificamente das obras de Nietzsche e Heidegger. Se o autor desejasse, poderia escrever um livro somente apresentando essas interpretações e isso já seria motivo de mérito. Imagino que essas interpretações possam contribuir para o enriquecimento dos debates entre os especialistas. Dessa forma, a obra também pode ser utilizada por um especialista interessado em conhecer e avaliar interpretações novas.

Por fim, a última parte da obra oferece um exemplo bem-sucedido de um diálogo entre arte e filosofia. O autor aplica o método fenomenológico-hermenêutico em sua análise das obras de arte. Não há nada de gratuito nessa análise: ela é a confirmação da principal tese do livro. Esse é o momento no qual o autor acrescenta à complexidade conceitual de suas apresentações anteriores a leveza das formas sensíveis. Diferentemente de um filósofo que se enclausura nos edifícios da especulação e nutre um verdadeiro temor pela simplicidade 
dos exemplos, no final da obra, M. Casanova apresenta imagens que supostamente - o escritor da resenha ainda não está convencido disso - comprovam a legitimidade do projeto central. Além de toda complexidade filosófica, o autor ainda expõe no final as "coisas mesmas". Claro, isso se comprarmos a eficácia da aplicação do método fenomenológico na análise das obras de arte...

\section{Exposição dos conteúdos}

Pretendo apresentar em termos gerais no que consiste os principais momentos dessa obra. A síntese que aqui terá seu lugar está longe de representar em detalhes a complexidade dos passos do livro. O objetivo é somente reconstruir os principais momentos, para que o leitor tenha condições de compreender ao menos o plano de desenvolvimento da obra.

O ponto de partida do autor é um diagnóstico sobre a crise do mundo contemporâneo. Essa crise atravessa os mais diversos campos da experiência humana: o conhecimento, a justiça, a religião, a política, a arte etc. $\mathrm{O}$ objetivo principal do livro é pensar uma possibilidade específica que surge em meio à crise. Essa possibilidade é a experiência do tempo como eternidade frágil. Tal experiência existe somente no contexto histórico específico do mundo contemporâneo. Fica evidente, portanto, que para o autor, experiências de temporalidade existem no interior de contextos históricos. É o que autor chamar de tempo do mundo.

Somente essa exposição mínima é suficiente para compreendermos a complexidade da obra. Afinal, o que é uma experiência de temporalidade? O que é mundo? Que tipo de relação estranha há entre temporalidade e época? São tantos conceitos abstratos reunidos em sínteses aparentemente obscuras...

O autor não foge dessas perguntas. Não parece estar de modo algum interessado em proliferar certa linguagem heideggeriana acessível somente para iniciados. Logo na introdução há uma exposição econômica do significado de cada termo. A complexidade dos objetos não impossibilita o esforço pela clareza.

Nessa exposição econômica, Casanova afirma que mundo é um horizonte finito e temporal a partir do qual nossos comportamentos e compreensões são possíveis. Importante mencionar que o termo mundo não pode ser confundido com a totalidade dos objetos naturais. Mundo é horizonte hermenêutico que fornece aos homens a compreensão do ente enquanto ente. $\mathrm{O}$ termo se refere muito mais à abertura de uma rede complexa de significados que possibilita as 
compreensões e os comportamentos. Vale ressaltar que mundo é finito e temporal, ou seja: essa rede complexa de significados representa sempre um momento histórico. Dado o caráter finito do mundo, é razoável admitir que existem outras épocas com outros conjuntos de significados.

Dentro desse contexto, a ideia de temporalidade do mundo pode ser apreendida com certa facilidade. Se o mundo é condição de possibilidade de todas as compreensões existentes do contexto $\mathrm{X}$ e os homens que vivem em $\mathrm{X}$ possuem alguma compreensão de temporalidade, segue-se que essa compreensão é possibilitada pelo mundo. Há portanto, um tempo do mundo. O esforço do autor é tentar apresentar no que consiste essa temporalidade.

Essa tarefa não parece muito difícil. Afinal, se todos que vivem em um mundo compreendem os significados possibilitados por ele, os homens contemporâneos conhecem com clareza o tipo de experiência temporal característico da contemporaneidade.

Contra essa facilitação, Casanova afirma que não somos boas testemunhas. $\mathrm{Na}$ verdade, a imersão no mundo impede uma compreensão clara dos significados sedimentados. O fato de utilizarmos com certa familiaridade diversos termos não significa que eles sejam claros para nós. Muito pelo contrário, o excesso de familiaridade dificulta o acesso, na medida em que o uso dos termos "funciona". O sucesso do uso impede a distância exigida pela descrição rigorosa. Por mais que possam usar o termo "tempo" milhares de vezes, os homens não possuem clareza no que diz respeito ao seu significado ${ }^{6}$.

Mas se a noção de mundo for realmente tão abrangente quanto parece, segue-se que nenhum homem está em condições de "sair do próprio mundo" e apresentar filosoficamente o significado da temporalidade em questão. Todo e qualquer processo de análise e "purificação" conceitual sempre irá pressupor a familiaridade. Qualquer compreensão sobre o tempo do mundo, por ser possibilitada pelo próprio mundo, será conseqüência da imersão.

A hipótese apresentada na introdução é a de que certos entes paradigmáticos apresentam aos homens o tempo do mundo. Esses entes são as obras de arte. Nelas, o tempo de um mundo específico se apresenta enquanto tal. Mas além de simplesmente expressar a temporalidade de um mundo, a obra também aponta para o que Heidegger chama de terra ${ }^{7}$.

6É importante mencionar que o autor não está buscando o significado a-histórico do termo tempo. Trata-se do significado tal como ele se apresenta no contexto histórico específico da contemporaneidade.

7É impossível entrar em detalhes sobre a complexa noção de "terra". Essa resenha, que já virou 
resenha crítica do livro de Marco

Casanova "Eternidade Frágil:

ensaio de temporalidade na arte"

O objetivo do autor, portanto, consiste em mostrar, através da descrição de algumas obras de arte, uma possibilidade de experiência temporal que surge especificamente no mundo contemporâneo. Esse é o "projeto central" tão mencionado na sessão antecedente.

Na primeira parte do livro, Casanova pretende analisar de que forma se dá a relação entre arte e mundo. A partir desse mote, o autor inicia uma reconstrução de alguns importantes momentos da filosofia da história a partir de Kant. Primeiro, expõe sinteticamente o projeto geral da filosofia crítica, com o objetivo de mostrar a relação entre Deus - postulado prático da razão - e a filosofia da história kantiana. Depois, apresenta as críticas de Hegel ao projeto kantiano, assim como o próprio projeto hegeliano de uma fenomenologia do espírito. Após o término desse capítulo, Casanova expõe de que modo o projeto de Dilthey supera o idealismo absoluto de Hegel, além de elaborar uma reconstrução elegante dos mais variados aspectos da filosofia da história diltheyana.

O ponto culminante dessa longa apresentação é a discussão sobre o conceito de mundo na filosofia de Martin Heidegger. Devido à proposta de união entre fenomenologia e hermenêutica, Heidegger supera os impasses do historicismo de Dilthey, mas enfatiza que o significado ideal dos objetos está sempre restrito a um mundo histórico. $\mathrm{O}$ autor, então, realiza uma reconstrução do programa e dos aspectos principais de Ser e Tempo, ressaltando o seu diagnóstico de que essa obra possui um problema estrutural: as ressignificações, que são conseqüências dos processos de singularização, não são suficientes para explicar a unidade do mundo.

Segundo o autor, por esse motivo a noção de acontecimento apropriador (Ereignis) passa a ter um lugar especial na filosofia do segundo Heidegger. Ao invés de pensar os significados do mundo a partir dos processos de singularização do ser-aí, na filosofia posterior à viragem, Heidegger defende que o acontecimento do "aí" depende do envio do ser. Mundo é fundamentalmente a essenciação do ser. Não o ser supremo, que é mais um modo de entificação, mas o ser que guarda uma diferença radical em relação a qualquer tipo de ente. Esse ser possibilita um mundo histórico (envio do ser), mas sempre se retrai no abismo da diferença (negatividade).

praticamente um artigo, sofreria uma outra transformação: se aproximaria de uma monografia. De acordo com a minha interpretação, a simples ideia de tempo do mundo, sem a menção ao termo terra, é suficiente para compreendermos minimamente o significado geral da noção de eternidade frágil. Peço desculpas ao leitor pela falta de explicação. Mas ficará claro que essa ausência não prejudica a compreensão do desenvolvimento do texto. 
"Eternidade Frágil: um exemplo de história à serviço da vida" por Renan da Rocha Cortez resenha crítica do livro de Marco

Casanova "Eternidade Frágil:

ensaio de temporalidade na arte"

A primeira parte termina com uma reconstrução de A origem da obra de arte. Essa reconstrução é crucial, pois nesse momento o autor apresenta de que modo se dá a relação entre obra de arte e mundo. Com o acréscimo da noção de terra, o autor explica detalhadamente nesse capítulo o significado da expressão temporalização do tempo do mundo. No fim dessa primeira parte, portanto, o leitor já terá clareza em relação ao significado amplo - não somente o "econômico" oferecido na introdução - do conceito de mundo, assim como terá condições de compreender no que consiste a relação existente entre obra de arte e mundo.

Os passos seguintes do projeto são dados na segunda parte do livro. O autor busca explicar nesse momento o que caracteriza de modo determinante a contemporaneidade e que tipo de experiência de temporalidade é possível nesse mundo. Segundo Casanova, a experiência de temporalidade do mundo contemporâneo é um desdobramento da noção nietzschiana de eterno retorno. O argumento central da obra, portanto, é retirado da filosofia de F. Nietzsche.

O ponto de partida da interpretação é uma exposição sobre o niilismo. Segundo o autor, esse termo significa a desvalorização dos valores supremos. Mas que valores seriam esses? Casanova identifica no poema de Parmênides o início de uma longa tradição que cultivou esses valores. Essa tradição privilegiou o ser, a unidade e o suprassensível em detrimento do devir, da multiplicidade e do sensível. O problema desse tipo de postura, segundo Casanova, está no fato de que nós, homens finitos cuja linguagem está contaminada por elementos "impuros" da empiria e da historicidade, não temos condições de acessar o mundo verdadeiro almejado pelos metafísicos.

Por ter assimilado a ideia de que não faz sentido viver em um mundo sem as categorias metafísicas tradicionais, o niilista, ao se deparar com a derrocada da metafísica, se desespera. Mas esse desespero ainda é expressão da voz da tradição. Somente por aceitar que o mundo do devir é constituído por um déficit ontológico, o niilista não suporta uma existência sem metas, ser e unidade. Em meio ao desespero, uma pergunta tranqüila precisa ser feita: afinal, por que aceitar a ideia de que sem categorias metafísicas tradicionais o mundo seria um caos completo? Nietzsche pretende, portanto, investigar a validade de um pressuposto velado da tradição, um preconceito moral que animou grande parte das aventuras metafísicas dos autores clássicos. Do ponto de vista geral, esse preconceito se caracteriza por dois tipos de avaliação: (1) os valores são constituídos por opostos e (2) um dos lados dos opostos é mais valioso do que o outro. Exemplos: o ser vale mais que o devir, a verdade é mais valiosa que a mentira, a essência é superior à aparência etc. 
"Eternidade Frágil: um exemplo de história à serviço da vida" por Renan da Rocha Cortez resenha crítica do livro de Marco

Casanova "Eternidade Frágil:

ensaio de temporalidade na arte"

A dúvida em relação à validade desses avaliações morais é fundamental para o que Casanova chama de filosofia experimental nietzschiana. Tal filosofia consiste justamente em colocar sob "experimento" a avaliação moral tradicional dos metafísicos. Será mesmo impossível viver em um mundo no qual o devir é soberano? Por que o mundo das mudanças não pode ser pleno?

Segundo o autor, o caminho trilhado por Nietzsche é semelhante ao apresentado por Descartes nas meditações. A analogia não é de conteúdo. Casanova não está afirmando que Nietzsche pretende encontrar uma verdade clara e distinta. A semelhança está na forma do método. O objetivo principal de Nietzsche é saber se o mundo do devir nos fornece algo que possa evidenciar o equívoco da tradição metafísica. Tendo isso em vista, propõe o que o autor chama (o termo não é de Nietzsche) de pessimismo hiperbólico. Tal pessimismo consiste basicamente em levar até as últimas conseqüências a ideia de que o mundo sem categorias metafísicas é insuportável. Trata-se de uma radicalização do niilismo: se, mesmo após a dose mais exagerada de pessimismo, algo resistir, o desespero do homem sem Deus deve ser abandonado. Como deve ter ficado nítido para o leitor, há semelhantes entre o pessimismo hiperbólico e a dúvida metódica de Descartes.

O pessimismo hiperbólico é estruturado em 6 passos. De um modo geral, nos 5 primeiros passos o autor pretende mostrar que a ontologia da vontade de poder é uma conseqüência natural da supressão das categorias metafísicas. $\mathrm{O}$ sexto passo é o que mais interessa para a resenha.

O último passo confunde-se com a ideia de eterno retorno. Em um primeiro momento, Casanova expõe por quais motivos descarta as duas interpretações mais difundidas na bibliografia secundária sobre Nietzsche. Para o autor, o eterno retorno não é uma tese cosmológica, muito menos um imperativo ético. $\mathrm{Na}$ verdade, a hipótese do eterno retorno possui uma função metodológica, semelhante à função do gênio maligno nas meditações.

A ideia de que o mundo se resume a uma multiplicidade de configurações relativas e descartáveis é insuportável para o niilista. Sadicamente Nietzsche propõe ao niilista o eterno retorno, uma experiência de pensamento que radicaliza o desespero. É como se o filósofo estivesse propondo para o niilista: "Considere claramente essa existência totalmente sem metas, na qual todas as ações são engolidas pelo nada; agora imagine essa existência retornando eternamente da mesma maneira... Não há um estágio último, seja o juízo final, a sociedade sem classes, a paz perpétua ou a ausência de matéria: imagine esse vai-e-vem de coisas descartáveis, imagine esse fluxo como uma espécie de roda que gira eternamente sem qualquer tipo de meta..." 
"Eternidade Frágil: um exemplo de história à serviço da vida" por Renan da Rocha Cortez resenha crítica do livro de Marco

Casanova "Eternidade Frágil:

ensaio de temporalidade na arte"

Segundo Casanova, ao propor esse experimento, Nietzsche não está constatando algo sobre o mundo. Trata-se somente de uma artifício "psicológico", que tem como função a radicalização da experiência do niilismo. Como escapar de um niilismo tão radical? Nietzsche parece ter convidado o niilista para conversar na beira do abismo. Pior: mostrou bons motivos para o vôo resignado rumo ao nada. Nessa beira, talvez Nietzsche e seu amigo tenham encontrado Pascal apostando com alguns jogadores sem rumo...

A função metodológica expressa a primeira voz do eterno retorno. Contudo, segundo o autor, em Assim falou Zaratustra Nietzsche apresenta uma segunda voz. Essa outra possibilidade de pensar o eterno retorno está baseada na noção de portal do instante, que Nietzsche menciona na famosa passagem chamada Da visão e do enigma.

A compreensão de temporalidade presente na noção de portal do instante tem como ponto de partida uma crítica à reificação do passado e do futuro. A reificação consiste basicamente na ideia de um passado positivado, compreendido como algo que existe em si mesmo, independente do instante. Segundo a interpretação do autor, contra esse tipo de compreensão do tempo, Nietzsche propõe que passado e futuro são entes relativos, pois só existem no instante. $\mathrm{O}$ corte do instante abre pela primeira vez a possibilidade do passado e do futuro. Nos termos do próprio autor, passado e futuro são termos para designar um certo modo de a temporalidade se constituir no instante.

Como conseqüência natural desse raciocínio, é necessário concluir que todo passado e todo futuro existem no instante. A impossibilidade de pensarmos um passado positivado, cuja existência independe do instante, é categórica. Não é possível elaborar uma diferenciação entre acontecimentos do passado que não dependem do instante e acontecimentos que dependem. Ora, disso segue-se que no instante ocorre uma reunião do todo da temporalidade. Por isso, todo instante carrega a eternidade.

A segunda voz do eterno retorno possibilita um novo uso da categoria de eternidade. Ao contrário do que muitos pensam, a morte de Deus e o fim da metafísica não inviabilizam a categoria do eterno. Obviamente Casanova não se refere a uma eternidade de duração infinita, pois a ideia de duração pressupõe um passado e um futuro reificados. Muito menos à eternidade de um ser incorruptível, cuja existência nada tem a ver com as mudanças do mundo das lamentações. Essa eternidade é estranha, pois se compatibiliza com o devir. Só há o mundo do vir-a-ser, mas todo instante fugaz é eterno. Em suma: eternidade frágil.

A segunda voz do eterno retorno, portanto, evidencia que o mundo do devir 
não é caracterizado por um déficit ontológico. Na verdade, todo instante é pleno, pois nele a totalidade se apresenta.

De acordo com a interpretação heideggeriana da filosofia de Nietzsche, a união entre vontade de poder e eterno retorno representa a consumação da metafísica e o predomínio do mundo da técnica. Nietzsche é o último metafísico, não por postular um mundo suprassensível, mas por radicalizar o esquecimento da diferença entre ser e ente. O principal mérito da obra de Casanova está em apontar que Heidegger considera somente a primeira voz do eterno retorno. Mas e se o filósofo da floresta negra considerasse a segunda? Que conseqüências teria para o seu projeto? Talvez essa pergunta sintetize os principais interesses que guiam Casanova nessa obra.

A experiência da eternidade frágil não é um mero retorno a um mundo místico perdido. Essa temporalidade não possibilita qualquer tipo de redenção: com ela não retornamos aos braços consoladores de Deus. Como ficou claro, a experiência da eternidade frágil é somente a experiência da totalidade do tempo no instante.

Essa experiência também não promove uma superação do niilismo e do mundo da técnica. Tal superação, segundo Casanova, não pode ser produzida por qualquer tipo de experiência em particular. Ela depende do envio do ser, do acontecimento apropriador que funda um mundo histórico. Nós vivemos no mundo da técnica e do niilismo. É impossível abandoná-lo, seja por atos de vontade, revoluções ou modificações radicais nas produções artísticas. Contudo, essa experiência de temporalidade existe justamente nesse mundo. Isso significa que não estamos condenados a experimentar somente a fluidez proporcionada pela vontade de vontade. A eternidade frágil é uma possibilidade de experiência presente no interior do mundo da técnica.

O terceiro e último momento da obra é propriamente onde o projeto se consolida. A responsabilidade de Casanova nesse momento é muito grande. Se todos os passos dados pelo livro estão corretos, as obras de arte realmente apresentam a temporalidade do mundo contemporâneo. Tal resultado é fruto de uma longa especulação. Um leitor deve, portanto, após compreender com clareza todos os passos, perceber que as obras apresentam a temporalidade do mundo, ou seja, a eternidade frágil. Em última instância Casanova está dizendo para o leitor: "veja".

A responsabilidade aumenta mais ainda na medida em que o autor aplica o método fenomenológico na análise das obras. Não interessa a ele saber quais eram as intenções do artista, ou que tipo de lugar ele ocupa no interior de um movimento de vanguarda. $\mathrm{O}$ autor aposta na acuidade fenomenológica: a descrição dos quadros, sem a interferência de pressupostos teóricos, pode nos mos- 
trar a temporalidade do nosso mundo. Casanova não está interessado em fazer historiografia da arte. Seu objetivo é somente mostrar, mesmo se isso contrastar com a biografia do artista e as informações historiográficas específicas, o que a obra realmente revela.

\section{Conclusão}

É hora de montar o quebra-cabeça. Pretendo expor aqui de maneira pontual por quais motivos essa obra de Casanova pode ser considerada um exemplo de história à serviço da vida.

Primeiro é importante mencionar dois aspectos: o autor parte de um problema existencial do presente e não simula imparcialidade. O problema existencial é a crise. Esse problema é o corte, o princípio que leva o autor a se confrontar com a multiplicidade dos fatos empíricos. M. Casanova não está preocupado somente em discutir os mínimos detalhes dos argumentos dos filósofos. Isso seria se perder, se resignar diante do mundo multiforme da história da filosofia e das infinitas possibilidades de interpretação presentes nas bibliografias secundárias em geral. Ao contrário da resignação, o interesse principal do autor é saber como os filósofos podem contribuir, seja para esclarecer a situação da crise ou para apresentar uma possibilidade singular de experiência em meio à ela. Não há simulação de imparcialidade: o interesse do autor é evidente.

Além do problema e do interesse, Casanova propõe um programa geral. Esse programa é fruto de um diálogo criativo com Nietzsche e Heidegger. Não seria exagerado afirmar que o autor propôs uma confrontação com esses autores, no sentido específico que Heidegger entende esse termo.

Há também a eleição de documentos. Parte da interpretação de Nietzsche está baseada no prestígio dado pelo autor a alguns aforismos póstumos específicos. Um especialista poderia questionar o modo como Casanova usa os póstumos; poderia questionar a pouca importância dada para muitos aforismos relevantes da obra publicada ${ }^{8}$. Mas o ponto é que Marco Casanova não está tão interessado em reconstruir o "em si" do pensamento de Nietzsche. A eleição dos documentos obedece aos imperativos do diálogo proposto pelo autor.

8 Vale lembrar que a obra publicada também é consultada e possui um peso central no argumento do autor. 
resenha crítica do livro de Marco

Casanova "Eternidade Frágil:

ensaio de temporalidade na arte"

Seria grosseiro do ponto de vista hermenêutico confundir interpretação seletiva com arbitrariedade. A base empírica foi consultada e apresentada no próprio livro em forma de citação. Não há desrespeito às fontes. Mas o contato com as fontes e a mera reconstrução da multiplicidade não são os objetivos principais. A multiplicidade dos documentos é organizada de acordo com a unidade de plano do próprio autor.

Por fim, em relação especificamente à discussão sobre a interpretação heideggeriana da filosofia de Nietzsche, Casanova propõe algo ousado. Se por um lado afirma que Heidegger não percebeu a segunda voz do eterno retorno, por outro insere essa segunda voz no interior do próprio contexto da filosofia heideggeriana. Nesse livro o autor não recusa a interpretação de Heidegger simplesmente por se incomodar com a associação entre Nietzsche e metafísica. Mas também não segue fielmente a interpretação heideggeriana, deixando claro para os leitores o que ela não apresentou.

A noção de tempo do mundo não é de Nietzsche. A associação entre a segunda voz do eterno retorno e a temporalidade do mundo contemporâneo só é possível no contexto especulativo do segundo Heidegger. Seria totalmente estranho para Nietzsche esse tipo de apropriação. Também não seria familiar à Heidegger a ideia de que Nietzsche propõe a eternidade frágil. Estranho para os dois, mas possível a partir dos dois. Nessa história da filosofia à serviço da vida, Casanova enfatiza, portanto, uma possibilidade de experiência que difere em alguma medida do devir corrosivo. Essa possibilidade só vem à tona no mundo da técnica. Eternidade frágil: nem superação, nem retorno, nem resignação.

Recebido em: 31.08.2014 | Aprovado em: 05.09.2014

CASANOVA, M.A. Compreender Heidegger. Rio de Janeiro: Editora Vozes, 2010.

Eternidade Frágil: Ensaios sobre temporalidade e arte. Rio de Janeiro: Editora Via Veritas, 2013.

.Interpretação enquanto princípio de constituição de mundo. Cadernos Nietzsche 10. São Paulo: 2001, p. $27-47$
.Nada a caminho: impessoalidade e técnica na obra de Martin Heidegger. Rio de janeiro: Editora Forense universitária, 2006

.O instante extraordinário: vida, história e valor na obra de Friedrich Nietzsche. Rio de Janeiro: Forense Universitária, 2003.

DAVEY, N. Nietzsche's aesthetics and the question of 
hermeneutic interpretation. British Journal of Aesthetics, Vol. 26, No 4, 1986.

NIETZSCHE, F. Assim Falou Zaratustra. Tradução de Mário da Silva. Rio de Janeiro: Civilização Brasileira, 2008

Segunda consideração intempestiva: da utilidade e desvantagem da história para a vida. Tradução de Marco Antônio Casanova. Rio de Janeiro: Relume Dumará, 2003.

JENSEY, A.K. Nietzsche and neokantian historiography: points of contact. Kriterion, Belo Horizonte, Número 128, dez/2013, p.283-400.

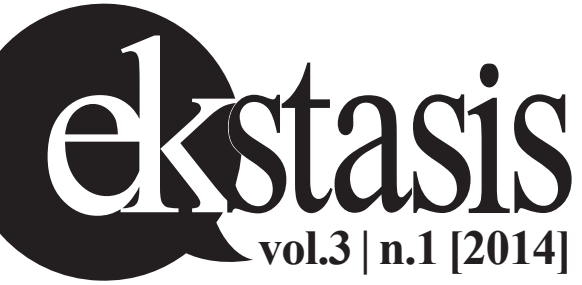

